\author{
Military Technical College \\ Kobry El-kobbah, \\ Cairo, Egypt
}

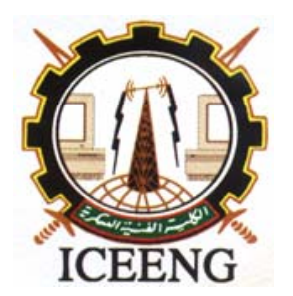

\author{
$5^{\text {th }}$ International Conference \\ on Electrical Engineering \\ ICEENG 2006
}

\title{
TUNING PID CONTROLLER FOR LOAD FREQUENCY CONTROL USING PARTICLE SWARM OPTIMIZATION TECHNIQUE
}

\author{
H. E. Mostafa
}

\begin{abstract}
:
This paper describes the application of Particle Swarm Optimization (PSO) technique to optimize a PID controller parameters for Load Frequency Control (LFC). The robustness of the proposed controller is investigated through parameters variations and changing the magnitude of load disturbance. The simulation results show that the applied PSO-based PID controller is achieved good performance even in the presence of the generation rate constraint (GRC). A comparative study results is made between the $\mathrm{H}^{\infty}$ controller and the proposed one. The performance is shown to be better for the new PID controller.
\end{abstract}

Kew words: Load Frequency Control, PID control, Particle Swarm Optimization.

\section{1- INTRODUCTION:}

Load frequency control (LFC) is one of the most important functions in the domain of power system operation and control. To ensure the quality of the power supply, it is necessary to design a LFC controller which deals with the control of generator loading depending on the frequency. The design of adequate LFC controller faces two main obstacles characterizing the LFC models. Firstly, the system parameters are uncertain and do change with time due to the loading condition. Secondly, the system is highly nonlinear, due to the GRC of steam turbines.

The conventional control strategy for the LFC problem is to take the integral of the control error (secondary control loop) as the control signal. Zero steady-state frequency deviation can be achieved but its transient performance is unsatisfactory [1-2]. In the literature, it has been reported that the introduction of the PID controller reduces the stability boundary considerably

$*$ Lecturer, Faculty of Industrial Education, Suez Canal University, Suez, Egypt 
since the rise in any of the PID gains causes the instability of the LFC loop [3]. Recently, many techniques for designing LFC PID controllers are published [3-6].

PSO is a new technique for nonlinear optimization. It has the advantages of being a very simple concept and computation requirements. PSO is a population based optimization algorithm that is motivated from the simulation of social behavior. Each individual in PSO flies in the search space with a velocity that is dynamically adjusted according to its own flying experience and its companions' flying experience. Compared with other evolutionary algorithms, such as Genetic Algorithms (GAs), the PSO algorithm possesses some attractive properties such as memory and constructive cooperation between individuals, so it has more chance to "fly" into better solution areas more quickly [7].

A new robust load frequency PID based-PSO to optimize the controller parameter is presented in this paper. The proposed PID controller guarantees the stability of LFC loop for a wide change of power system parameters and GRC. Comparative results are given for both the $\mathrm{H}^{\infty}$ controller and the proposed one. The power system performance is shown to be better with the proposed controller given in this paper.

\section{2- LFC SYSTEM MODEL}

The block diagram of the LFC of a single area power system is shown in Fig. 1 [8].

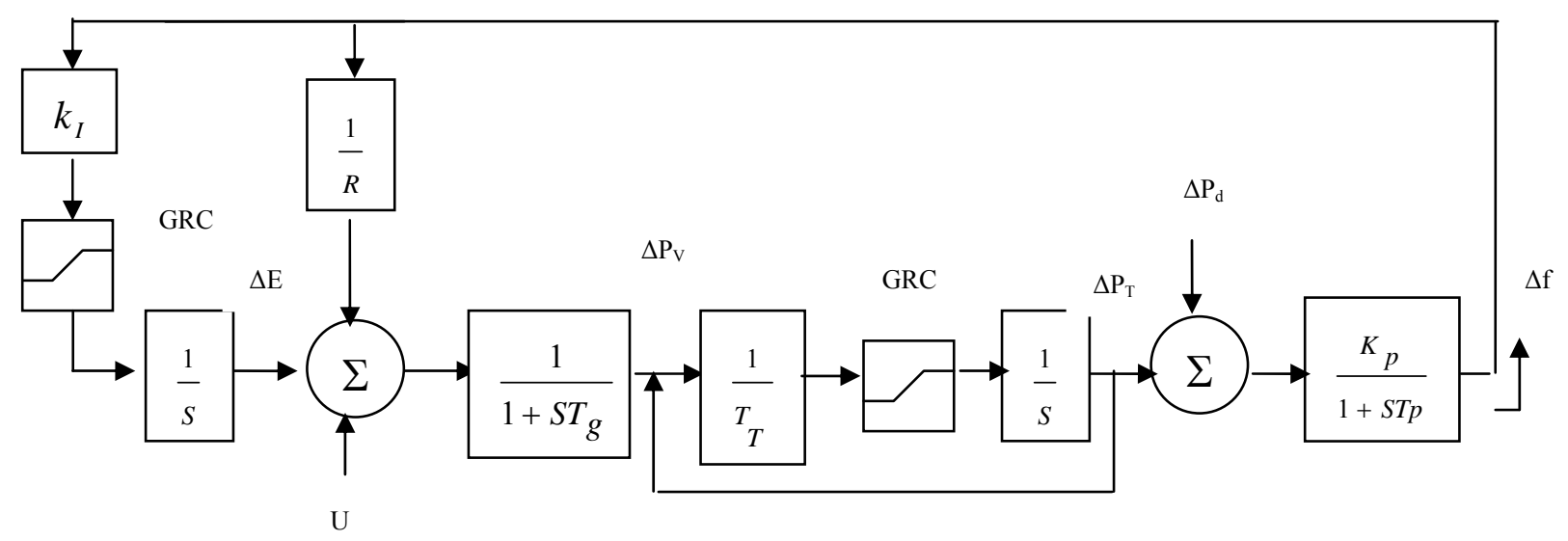

Fig. 1 Block diagram of a sample power system with GRC

The dynamic equations of this model can be rewritten in the state-space form as

$$
\dot{x}(t)=A x(t)+B u(t)+F \Delta P_{d}(t)
$$

The state vector and the system matrices are given by

$x(\mathrm{t})=\left[\Delta f(\mathrm{t}), \Delta P_{\mathrm{T}}(\mathrm{t}), \Delta P_{\mathrm{V}}(\mathrm{t}), \Delta E(\mathrm{t})\right]^{\mathrm{T}}$, 


$$
\begin{aligned}
& B^{\mathrm{T}}=\left[0,0,1 / T_{\mathrm{g}}, 0\right], \\
& F^{\mathrm{T}}=\left[-K_{\mathrm{p}} / T_{\mathrm{p}}, 0,0,0\right] \text {, and } \\
& A=\left[\begin{array}{cccc}
-\frac{1}{T_{P}} & \frac{K_{P}}{T_{P}} & 0 & 0 \\
0 & -\frac{1}{T_{T}} & \frac{1}{T_{T}} & 0 \\
-\frac{1}{R T_{g}} & 0 & -\frac{1}{T_{g}} & -\frac{1}{T_{g}} \\
K_{I} & 0 & 0 & 0
\end{array}\right]
\end{aligned}
$$

where,

$$
\begin{array}{ll}
\Delta & =\text { incremental change, } \\
\mathrm{R} & =\text { governor 's regulation constant }(\mathrm{Hz} / \mathrm{pu} \mathrm{MW}), \\
\mathrm{f}(\mathrm{t}) & =\text { frequency of the area }(\mathrm{Hz}), \\
\mathrm{E}(\mathrm{t}) & =\text { integral control signal }(\mathrm{pu} \mathrm{MW}), \\
\mathrm{P}_{\mathrm{d}}(\mathrm{t}) \quad=\text { load disturbance }(\mathrm{pu} \mathrm{MW}), \\
\mathrm{T}_{\mathrm{g}} \quad \text { = governor time constant }(\mathrm{s}), \\
\mathrm{T}_{\mathrm{T}} \quad \text { = turbine time constant }(\mathrm{s}), \\
\mathrm{T}_{\mathrm{p}} \quad=\text { plant model time constant }(\mathrm{s}), \\
\mathrm{K}_{\mathrm{p}} \quad \text { = plant gain, } \\
\mathrm{k}_{\mathrm{I}} \quad \text { integral control gain. } \\
\mathrm{U}_{\mathrm{s}} \quad \text { = supplementary control signal }
\end{array}
$$

The constraint to the rate of power generation is taken into consideration by adding limits to the turbine model. GRC is assumed to be $0.1 \mathrm{pu} / \mathrm{min}[8,9]$. similar limits are added to the integrator input to prevent excessive control action.

\section{3- BASIC METHOD OF PSO:}

Kennedy and Eberhart developed a PSO concept. The PSO is basically developed through simulation of bird flocking in two-dimension space. The position of each agent is represented by $\mathrm{XY}$ axis position and also the velocity is expressed by $v_{x}$ (the velocity in the $\mathrm{x}$ direction) and $v_{y}$ (the velocity in the $y$ direction). Modification of the agent position is realized by the position and velocity information.

Bird flocking optimizes a certain objective function. Each agent knows its best value so far (pbest), and its xy position. This information is analogous to the personal experience of each agent. Moreover, each agent knows the best value so far in the group (gbest) among the obtained pbests. This information is analogous to knowledge of how other agents in the group have performed. Namely, each agent tries to modify its position. Position modification can be 
represented by the concept of velocity. The velocity of each agent can be modified by the following equation $[10]:$ :

$$
v_{i}^{k+1}=K\left[v_{i}^{k}+c_{1} \text { rand }_{1} *\left(\text { pbest }_{i}-s_{i}^{k}\right)+c_{2} \text { rand }_{2} *\left(\text { gbest }_{-} s_{i}^{k}\right)\right]
$$

where, $\quad K=$ the constriction factor $=\frac{2}{\left|2-\varphi-\sqrt{\varphi^{2}-4 \varphi}\right|}, \quad$ and $\varphi=c_{1}+c_{2}, \varphi>4$

$v_{i}^{k} \quad$ : velocity of agent $\mathrm{i}$ at iteration $\mathrm{k}$,

$c_{j} \quad$ : weighting factor,

rand $_{j}$ : random number between 0 and 1 ,

$s_{i}^{k} \quad:$ current position of agent $\mathrm{i}$ at iteration $\mathrm{k}$,

pbest $_{i}$ : pbest of agent i,

gbest : gbest of the group.

The current position (searching point in the solution space) can be modified by the following equation:

$$
s_{i}^{k+1}=s_{i}^{k}+v_{i}^{k+1}
$$

\section{4- COMPUTER SIMULATION}

\subsection{Study system}

To account for the uncertainty in parameters and to allow for changes in operating conditions, the study system is represented by three models having different parameters [8]. Model A represents the design point for the two controllers under study. Models $\mathrm{B}$, and $\mathrm{C}$ represent a change in Model A parameters by $\pm 50 \%$ for $\mathrm{T}_{\mathrm{p}}$ and $\mathrm{T}_{\mathrm{t}}, \mathrm{T}_{\mathrm{g}}$, and $\mathrm{R}$ by $\pm 30 \%$. All these parameters are listed in Table 1.

Table 1 Study System Parameters for Different Models

\begin{tabular}{|c|c|c|c|c|c|c|}
\hline Model & $1 / \mathrm{T}_{\mathrm{p}}$ & $\mathrm{K}_{\mathrm{p}} / \mathrm{T}_{\mathrm{p}}$ & $1 / \mathrm{T}_{\mathrm{t}}$ & $1 / \mathrm{T}_{\mathrm{g}}$ & $1 / \mathrm{RT}_{\mathrm{g}}$ & $\mathrm{K}_{\mathrm{I}}$ \\
\hline $\mathrm{A}$ & 0.0666 & 8 & 3.663 & 13.736 & 6.86 & 0.05 \\
\hline $\mathrm{B}$ & 0.1 & 12 & 4.762 & 17.857 & 10.639 & 0.05 \\
\hline $\mathrm{C}$ & 0.0333 & 4 & 2.564 & 9.615 & 3.081 & 0.05 \\
\hline
\end{tabular}

\subsection{Design of PSO-based PID controller}

In the single area system shown in Fig. 1, the conventional integral controller is replaced by PID controller with the following structure: 


$$
G_{c}(s)=k k+\frac{k_{I}}{s}+k_{d} s
$$

where

$\mathrm{kk} \quad=$ proportional control gain. \& $\quad \mathrm{k}_{\mathrm{d}} \quad=$ differential control gain.

A Particle Swarm Optimization Toolbox (PSOt) for use with the Matlab scientific programming environment has been developed in [11]. It is modified and employed to get the optimal values of parameters according to the given predefined ranges. In addition to the main PSO program, additional programs were designed to get the state-space representation of the system.

\section{Objective function:}

To increase the system damping, the eigenvalue-based objective function is considered as follows:

$$
J=\min \left\{\varsigma_{i}\right\}
$$

where $\varsigma_{i}$ is the damping ratio of the ith electromechanical mode eigenvalue. In the optimization process, it is aimed to maximize $J$ in order to increase the damping of the poorly damped electromechanical modes. The optimization problem can be formulated as follows:

maximize $(J)$ subject to

$$
\begin{aligned}
& k k^{\min } \leq k k \leq k k^{\max } \\
& k_{I}^{\min } \leq k_{I} \leq k_{I}^{\max } \\
& k_{d}^{\min } \leq k_{d} \leq k_{d}^{\max }
\end{aligned}
$$

Typical ranges of the optimized parameters are [-100:100] for all gains. The system A matrix after adding the PID signals becomes (with the same state vector as in eqn. 2):

$$
A=\left[\begin{array}{crrr}
-\frac{1}{T_{P}} & \frac{K_{P}}{T_{P}} & 0 & 0 \\
0 & -\frac{1}{T_{T}} & \frac{1}{T_{T}} & 0 \\
-\left[\frac{1}{R T_{g}}+\frac{k k}{T_{g}}-\frac{k_{d}}{T_{g} T_{p}}\right] & -\frac{k_{p} k_{d}}{T_{g} T_{p}} & -\frac{1}{T_{g}} & -\frac{1}{T_{g}} \\
K_{I} & 0 & 0 & 0
\end{array}\right]
$$

The obtained values of the PID gains using PSO are: $\mathrm{kk}=0.0114, \mathrm{k}_{\mathrm{I}}=0.1218, \mathrm{k}_{\mathrm{d}}=0.3077$;

\subsection{Design of $\mathbf{H}^{\infty}$ controller}


In order to provide an efficient base of comparison, a robust controller based on $\mathrm{H}^{\infty}$ optimal regulator [12] is deigned for the parameters of model A. Reference [13] propose a robust, fixed-parameters controller using the standard $\mathrm{H}^{\infty}$-optimal regulator for power system LFC. The controller uses only the frequency deviation of the system as a feedback signal. The application of the $\mathrm{H}^{\infty}$ controller design procedure to the study system produces a third order controller in the form

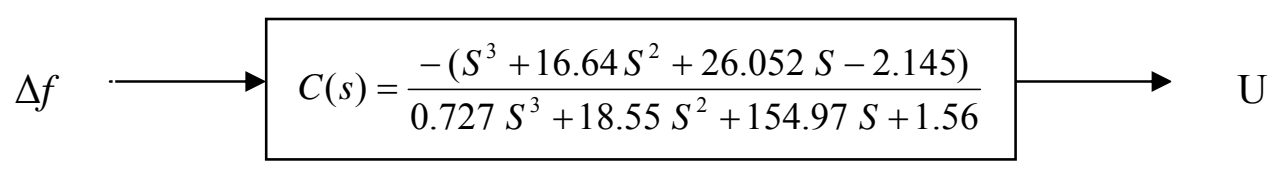

Fig. $2 \mathcal{H}^{\infty}$ LFC controller block diagram

The input to the $\mathrm{H}^{\infty}$ controller is the system frequency deviation and its output is the supplementary control signal. Fig. 2 depicts the block diagram model developed to simulate the LFC system equipped with the $\mathrm{H}^{\infty}$ controller.

Power systems constantly experience changes in the operating condition due to variations in generation and load patterns, as well as changes in the transmission network. As a result, there is a corresponding large variation in the small signal dynamic behavior of the system. This can be expressed as a parametric uncertainty in the small signal linearized model of the plant.

\section{4- Comparative study}

The reliability of the proposed PSO-based PID controller is evaluated through a comparison of its response with that of the $\mathrm{H}^{\infty}$ controller. In order to inspect their robustness, the two controllers are applied to the LFC models based on the three considered sets of parameters (models A, B, and C). Another test of robustness is performed by using two different magnitudes of step load disturbances; namely, $-1 \%$ and $-0.5 \%$. The importance of this test stems from the nonlinear characteristic of the system which is mainly caused by the GRC. The applied case studies are listed in Table (2).

Table (2) List of Applied Case Studies

\begin{tabular}{|c|c|c|c|c|c|c|}
\hline Case Study & 1 & 2 & 3 & 4 & 5 & 6 \\
\hline Model & $\mathrm{A}$ & $\mathrm{A}$ & $\mathrm{B}$ & $\mathrm{B}$ & $\mathrm{C}$ & $\mathrm{C}$ \\
\hline Disturbance & $-1 \%$ & $-0.5 \%$ & $-1 \%$ & $-0.5 \%$ & $-1 \%$ & $-0.5 \%$ \\
\hline
\end{tabular}

\section{5- SIMULATION RESULTS}

The simulation results are illustrated in six figures (Fig. 3-5). Each figure represents a case study showing the responses of the LFC with the two considered controllers

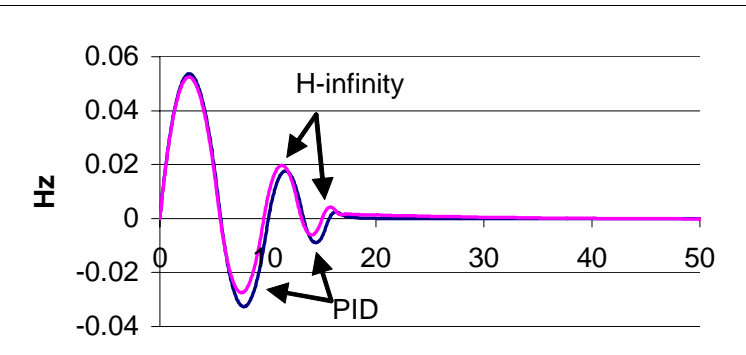




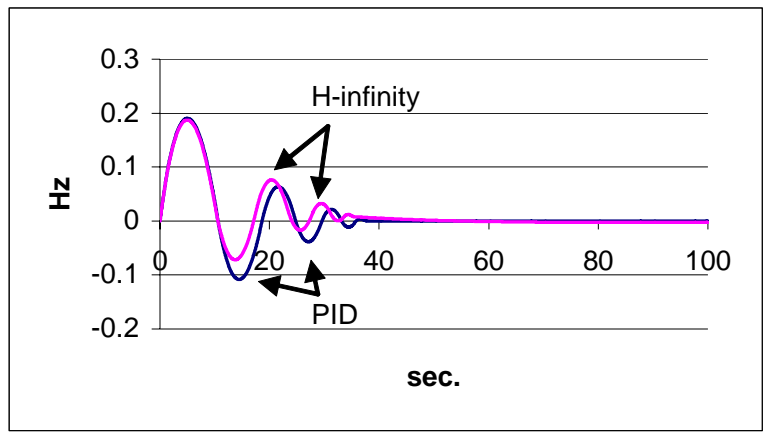

3 a

Fig. 3 Model A response to: a) $-1 \%$, and b) -0.5 step change in load

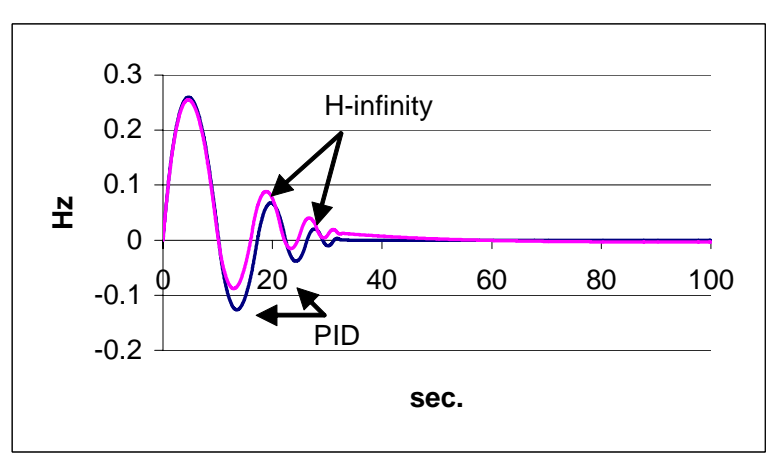

$4 \mathrm{a}$

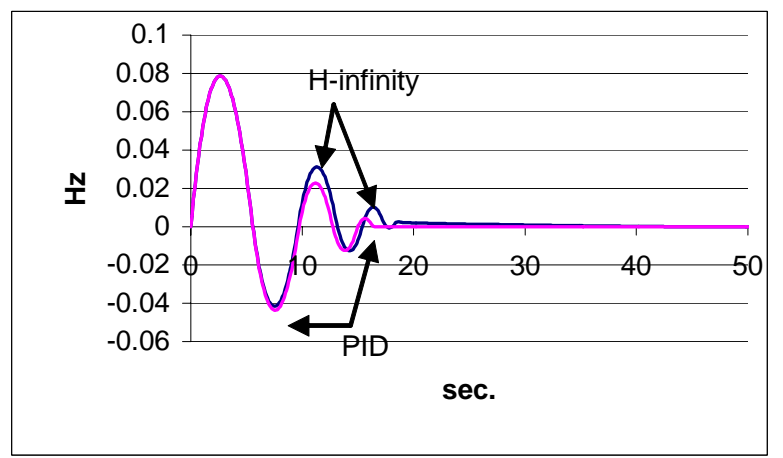

$4 \mathrm{~b}$

Fig. 4 Model B response to: a) $-1 \%$, and b) -0.5 step change in load

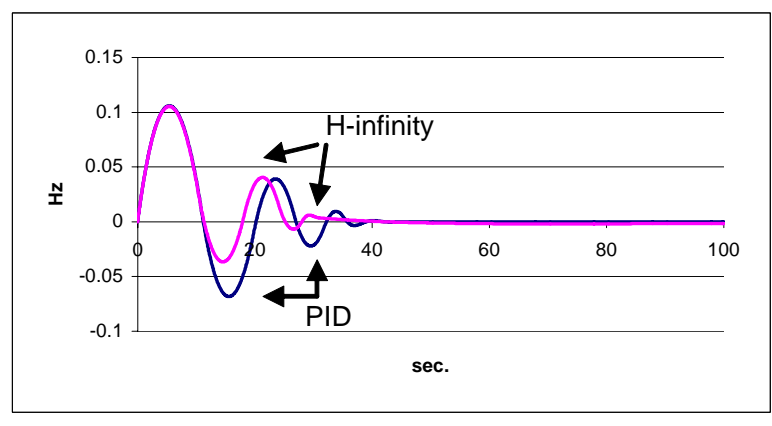

$5 \mathrm{a}$

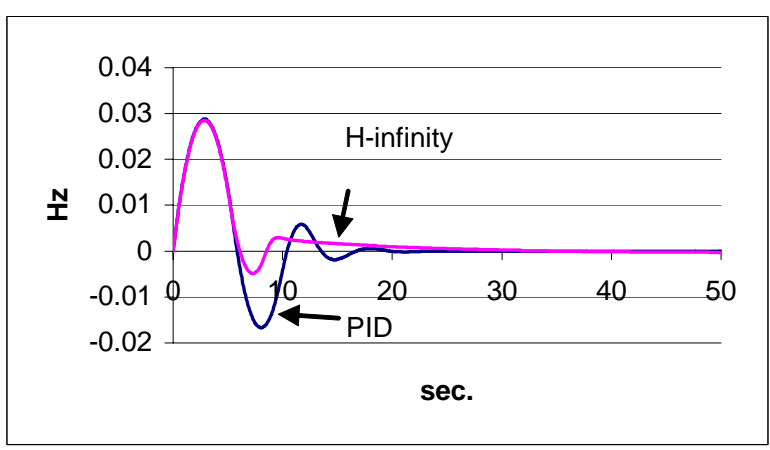

$5 b$

Fig. 5 Model C response to: a) $-1 \%$, and b) -0.5 step change in load

The qualitative analysis of the obtained results may lead to the following conclusions: 
1- The first overshoot is almost the same for the two controllers. This is a result of using maximum control effort, limited by GRC.

2- The transient performance of the two controllers are similar.

The quantitative comparison is based upon three requirements for optimizing the transient response: minimize overshoot, minimize settling time, and minimize system time deviation. The settling time is calculated when the frequency reaches $5 \%$ of the static frequency drop $\left(\Delta f_{\mathrm{o}}\right)$. Where

$$
\Delta f_{\mathrm{o}}=\Delta f_{o}=\frac{\Delta P_{d}}{D+\frac{1}{R}}
$$

The system time deviation (synchronous time, or time error) is defined by

$$
\tau=\frac{1}{f_{o}} \int_{0}^{T} \Delta f d t
$$

Where, $f_{o}$ is the rated frequency ( $50 \mathrm{~Hz}$ in our case), and $T$ is the study period.

Since the maximum overshoot is almost constant irrespective of the controller type, this quantity is excluded from the quantitative comparison. The other two quantities (settling time and synchronous time), are extracted from the time responses of each case study, and are recorded in Table 3.

Table (3) Performance Evaluation:

\begin{tabular}{|c|c|c|c|c|}
\hline \multirow{2}{*}{$\begin{array}{c}\text { Case } \\
\text { Study }\end{array}$} & \multicolumn{2}{|c|}{$\begin{array}{c}\text { Settling Time } \\
(\mathrm{s})\end{array}$} & \multicolumn{2}{c|}{$\begin{array}{c}\text { System Synchronous } \\
\text { Time }(\mathrm{ms})\end{array}$} \\
\cline { 2 - 5 } & PID & $\mathrm{H}^{\infty}$ & PID & $\mathrm{H}^{\infty}$ \\
\hline 1 & 37.95 & 178.15 & 18.8 & 29.8 \\
\hline 2 & 18.3 & 30.85 & 2.7 & 3.6 \\
\hline 3 & 32.85 & 200.55 & 26.6 & 39.6 \\
\hline 4 & 16.85 & 36.6 & 3.9 & 5 \\
\hline 5 & 41 & 127.85 & 10 & 16.5 \\
\hline 6 & 18.9 & 26.15 & 1.4 & 2.6 \\
\hline
\end{tabular}

Investigating the results recorded in this table leads to the following conclusions:

1. The settling time corresponding to the $\mathrm{H} \infty$ robust controller is greater than that of the PID controller.

2. The system synchronous time $\tau$ of the proposed PID controller is much smaller than that of the $\mathrm{H} \infty$ controller.

In summary, we can conclude that the proposed PSO-based PID controller exhibits better transient performance on the basis of daily evaluation.

\section{6- CONCLUSION}

In this paper, a new PID controller using PSO technique is applied to power system LFC. The controller uses the frequency deviation of the system as a single feedback signal. The system parametric uncertainties are obtained by changing the parameters by $30 \%$ to $50 \%$ from their 
typical values. The simulation results show that the applied PSO-based PID controller is possess good performance even in the presence of the GRC. The robustness of the proposed controller is investigated through parameters variations and changing the magnitude of load disturbance. The comparison to the other robust controller proves that both controllers have similar transient performance. However, on the basis of settling time and synchronous time, the proposed controller exhibits better performance in all case studies under consideration. An extra and important advantage of the proposed controller is its simple structure.

\section{REFERENCES}

[1] O. Elgerd, "Electric Energy Systems Theory, An Introduction" Second edition, TMH Edition, 1985.

[2] Hadi Saadat, "Power System Analysis" McGraw-Hill, second edition, 2002.

[3] J. Salerno, "Modified PID Load-Frequency Control with the Consideration of Valve Position Limits" IEEE Power Engineering Society, Winter Meeting, Vol. 1, pp 701-706, 1999.

[4] Y. Oysal, E. Koklikaya, and A.S. Yilmaz, "Fuzzy PID controller design for load frequency control using gain scaling technique" International Conference on Electric Power Engineering, Budapest, pp 178, 1999.

[5] Y.H. Moon, H.S. Ryu, J.G. Lee, and S. Kim, "Power system load frequency control using noise-tolerable PID feedback" IEEE International Symposium on Industrial Electronics, Vol. 3, pp. 1714-1718, 2001.

[6] A. Khodabakhshian, and N. Golbon, "Design of a New Load Frequency Pid Controller Using Qft" IEEE International Symposium on Intelligent Control, Mediterranean Conference on Control and Automation, pp 970-975, June 2005.

[7] C. Zhang, H. Shao, and Y. Li, "Particle Swarm Optimization for Evolving Artificial Neural Network" IEEE International Conference on Systems, Man, and Cybernetics, Vol. 4, pp. 2487-2490, Oct. 2000.

[8] Y. Wang, R. Zhou and C. Wen, "Robust Load-Frequency Controller Design for Power Systems" IEE Proc. C, Vol. 140, pp. 11-16, Jan. 1993.

[9] A. Kumar, O. Malik and G. Hope, "Discrete Variable Structure Controller for Load Frequency Control of Multiarea Interconnected Power Systems" IEE Proc. C, Vol. 134, pp 116-122, 1987.

[10] J. Kennedy and R. Eberhart, "Swarm Intelligence", Book, Morgan Kaufmann Publishers, 2001.

[11] B. Birge, "PSOt - a particle swarm optimization toolbox for use with Matlab" Proceedings of the IEEE Swarm Intelligence Symposium, pp. 182-186, April 2003.

[12] H Kwakernaak, "Robust Control and $\mathcal{H}^{\infty}$ Optimization: Tutorial Paper", Automatica, Vol. 29, No. 2, pp. 255-273, 1993.

[13] H.E. Talaat, M.A. El-Sharkawy, H.E. Moustafa, and K. Yassin, "Robust LoadFrequency Control Based on $\mathrm{H}^{\infty}$-optimal Control" Scientific Bulletin, ASU, Faculty of Engineering, Vol. 34, No. 2, pp 201-214, June 1999. 